spinal flexion and a contributory factor to tragus-to-wall distance and cervical rotation.

Conclusion: In early axSpA, spinal mobility impairment is independently determined by clinical disease activity, MRI spinal inflammation and the severity of enthesitis. Maximal intermalleolar distance (which is not a true measure of spinal mobility) was the only measure not associated with MRI spinal inflammation. The influence of spinal inflammation prevails in the early phase of axSpA while spinal damage becomes more relevant in later disease stages.

References: None.

Disclosure of Interests: Pedro Carvalho: None declared, Ana Marreiros: None declared, Joao Eurico Fonseca: None declared, Adeline Ruyssen-Witrand Grant/ research support from: Abbvie, Pfizer, Consultant of: Abbvie, BMS, Lilly, Mylan, Novartis, Pfizer, Sandoz, Sanofi-Genzyme, Pedro M Machado Consultant of: PMM: Abbvie, Celgene, Janssen, Lilly, MSD, Novartis, Pfizer, Roche and UCB, Speakers bureau: PMM: Abbvie, BMS, Lilly, MSD, Novartis, Pfizer, Roche and UCB DOI: 10.1136/annrheumdis-2020-eular.5015

\section{OP0077 DETERMINANTS OF THE PHYSICIAN'S GLOBAL ASSESSMENT AND INFLUENCE OF CONTEXTUAL FACTORS IN EARLY AXIAL SPONDYLOARTHRITIS}

$\underline{\text { F. Hirano }}^{1}$, R. B. M. Landewée, ${ }^{2,3}$ F. A. Van Gaalen ${ }^{1}$, D. Van der Heijde ${ }^{1}$, C. Gaujoux-Viala ${ }^{4}$, S. Ramiro ${ }^{1,3} .{ }^{1}$ LUMC, Leiden, Netherlands; ${ }^{2}$ AUMC, Amsterdam, Netherlands; ${ }^{3}$ Zuyderland MC, Heerlen, Netherlands; ${ }^{4}$ Nîmes University Hospital, Nîmes, France

Background: In RMDs, the physician's global assessment (PhGA) is a major factor of treatment decision. It is not well-known which disease manifestations contribute to PhGA in early axSpA and if contextual factors have an impact. Objectives: To investigate determinants of PhGA and the influence of contextual factors on this relationship in patients with early axSpA.

Methods: Five-year data from DESIR, a cohort of early axSpA, were analysed. Clinical data were collected every 6 months up to 2 years and annually thereafter. The primary analysis included all patients, and the subgroup analysis patients with follow-up MRI at 2 and/or 5 years. PhGA over 5 years was the outcome of interest. Univariable generalized estimating equation (GEE) models were used to investigate relationships between potential determinants and PhGA. Longitudina relationships were investigated in autoregressive models. Effect modification by contextual factors (educational level, gender and age) was tested and, if significant, models were stratified. Univariable analyses were chosen to better assess the contributory explanatory effects of each of the determinants in each of the strata.

Results: A total of 708 patients were included, mean age 33.7 (SD 8.6) years, $46 \%$ male, $41 \%$ lower educated. The subgroup consisted of 220 patients with similar characteristics. Higher BASDAI questions 1-6, SJC28, TJC53, Maastrich Ankylosing Spondylitis Enthesitis Score (MASES), CRP and BASMI were associated with a higher PhGA (Table 1). Gender and age were effect modifiers of SJC28; the effect was largest in the younger male stratum $(\beta[95 \% \mathrm{Cl}] ; 1.07[0.71$, $1.43])$, and smallest in the older female stratum (0.13 [0.04, 0.22]) (Figure 1). Autoregressive GEE models revealed the same determinants of PhGA and the same pattern of effect modification by gender and age.

Conclusion: Patient's subjective symptoms, peripheral arthritis, enthesitis, higher CRP and impaired spinal mobility contribute to explain PhGA in patients with early axSpA irrespective of gender and age. But physicians consider the presence of swollen joints as more important in males than in females.
Figure. Impact of swollen joint count on the physician's global assessment across gender and age groups

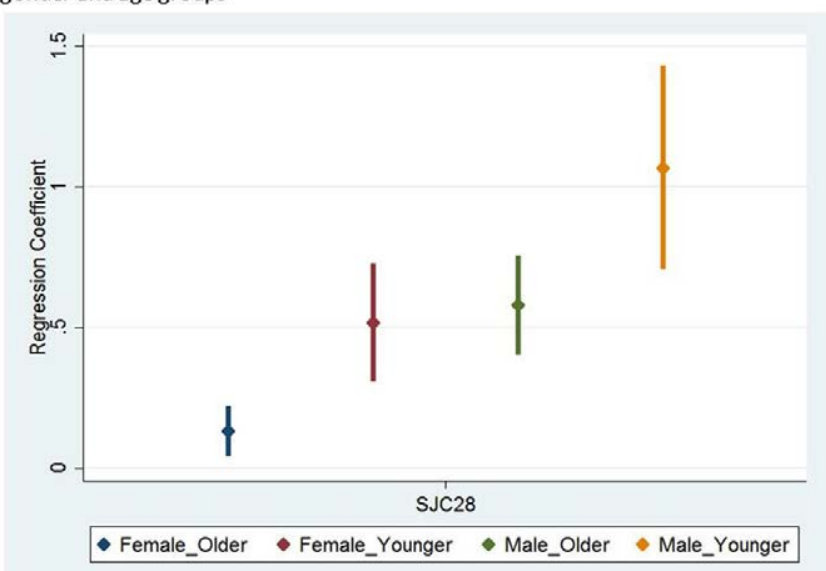

Regression coefficients $(95 \% \mathrm{Cl})$ of the effect of SJC28 on PhGA in the univariable GEE analyses across gender/age-stratified groups (in an ascending order).

Disclosure of Interests: Fumio Hirano Paid instructor for: Ono pharmaceuticals, Astellas Pharma Inc, Sumitomo Dainippon Pharma, Chugai Pharmaceutical Co. Ltd., Robert B.M. Landewé Consultant of: AbbVie; AstraZeneca; Bristol-Myers Squibb; Eli Lilly \& Co.; Galapagos NV; Novartis; Pfizer; UCB Pharma, Floris A. van Gaalen: None declared, Désirée van der Heijde Consultant of: AbbVie, Amgen, Astellas, AstraZeneca, BMS, Boehringer Ingelheim, Celgene, Cyxone, Daiichi, Eisai, Eli-Lilly, Galapagos, Gilead Sciences, Inc., Glaxo-Smith-Kline, Janssen, Merck, Novartis, Pfizer, Regeneron, Roche, Sanofi, Takeda, UCB Pharma; Director of Imaging Rheumatology BV, Cecile Gaujoux-Viala: None declared, Sofia Ramiro Grant/research support from: MSD, Consultant of: Abbvie, Lilly, Novartis, Sanofi Genzyme, Speakers bureau: Lilly, MSD, Novartis DOI: 10.1136/annrheumdis-2020-eular.843

\section{OP0078 \\ MAPPING FROM THE ANKYLOSING SPONDYLITIS DISEASE ACTIVITY SCORE (ASDAS) TO EQ5D IN PATIENTS WITH AXIAL SPONDYLOARTHRITIS}

M. Hernandez ${ }^{1}$, A. Wailoo' ${ }^{1}$, G. Chrysanthou' ${ }^{1}$, P. Carvalho², D. Van der Heijde $^{3}$, M. J. Santos ${ }^{4}$, P. M. Machado ${ }^{5}{ }^{1}$ University of Sheffield, Sheffield, United Kingdom; ${ }^{2}$ Centro Hospitalar Universitário do Algarve, Faro, Portugal; ${ }^{3}$ Leiden University Medical Centre, Leiden, Netherlands; ${ }^{4}$ Faculdade Medicina de Lisboa, Lisboa, Portugal; ${ }^{5}$ University College London, London, United Kingdom

Background: Clinical studies often omit outcomes that allow the direct estimation of Quality Adjusted Life Years (QALYs) for use in cost effectiveness analyses crucial for informing policy decisions. This means analysts often have to estimate the relationship, "map", between included outcomes and preference based ones like the EuroQoL EQ5D. In ankylosing spondylitis (AS), the relationship between BASDAI/BASFI and EQ5D has been established but the emergence and growing use of the Ankylosing Spondylitis Disease Activity Score (ASDAS), a new composite index used to assess clinical disease activity, means new mapping tools are required. Furthermore mapping has never been done for the entire axial

Table 1. Factors associated with PhGA over time in gender/age-stratified groups in univariable analysis

\begin{tabular}{|c|c|c|c|c|}
\hline & $\begin{array}{l}\text { Female/Older } \\
\qquad(n=200)\end{array}$ & $\begin{array}{l}\text { Female/Younger } \\
\qquad(n=181)\end{array}$ & $\begin{array}{l}\text { Male/Older } \\
(n=154)\end{array}$ & $\begin{array}{c}\text { Male/Younger } \\
\quad(n=173)\end{array}$ \\
\hline & \multicolumn{4}{|c|}{ Coefficient $(95 \% \mathrm{Cl})$} \\
\hline BASDAI Q1 (fatigue, 0-10) & $0.39(0.34,0.44)$ & $0.39(0.34,0.44)$ & $0.41(0.35,0.46)$ & $0.46(0.41,0.51)$ \\
\hline BASDAI Q2 (back pain, 0-10) & $0.49(0.45,0.54)$ & $0.53(0.49,0.57)$ & $0.48(0.43,0.53)$ & $0.58(0.54,0.63)$ \\
\hline BASDAI Q3 (peripheral joint pain, 0-10) & $0.31(0.27,0.36)$ & $0.36(0.31,0.41)$ & $0.32(0.27,0.37)$ & $0.43(0.37,0.48)$ \\
\hline BASDAI Q4 (enthesitis, 0-10) & $0.37(0.33,0.41)$ & $0.42(0.37,0.46)$ & $0.36(0.31,0.41)$ & $0.52(0.47,0.56)$ \\
\hline BASDAI Q5 (severity of morning stiffness, $0-10$ ) & $0.42(0.37,0.46)$ & $0.45(0.40,0.49)$ & $0.44(0.40,0.49)$ & $0.58(0.54,0.63)$ \\
\hline BASDAI Q6 (duration of morning stiffness, $0-10$ ) & $0.30(0.25,0.35)$ & $0.35(0.30,0.39)$ & $0.36(0.31,0.41)$ & $0.50(0.45,0.56)$ \\
\hline BASMI linear $(0-10)$ & $0.61(0.45,0.78)$ & $0.67(0.48,0.86)$ & $0.49(0.30,0.68)$ & $0.95(0.75,1.15)$ \\
\hline SJC28 (0-28) & $0.13(0.04,0.22)$ & $0.52(0.31,0.73)$ & $0.58(0.40,0.76)$ & $1.07(0.71,1.43)$ \\
\hline TJC53 (0-159) ף & $0.05(0.04,0.06)$ & $0.13(0.11,0.16)$ & $0.13(0.11,0.16)$ & $0.15(0.13,0.18)$ \\
\hline MASES (0-39) & $0.10(0.08,0.12)$ & $0.15(0.12,0.17)$ & $0.18(0.14,0.23)$ & $0.30(0.25,0.35)$ \\
\hline $\mathrm{CRP}(\mathrm{mg} / \mathrm{L})$ & $0.02(0.01,0.04)$ & $0.03(0.01,0.05)$ & $0.06(0.04,0.07)$ & $0.04(0.03,0.05)$ \\
\hline Any EAM (presence vs absence) & $-0.13(-0.49,0.23)$ & $-0.20(-0.58,0.19)$ & $-0.26(-0.68,0.17)$ & $-0.28(-0.69,0.14$ \\
\hline SPARCC-spine $(0-414) \S$ & $0.06(-0.11,0.22)$ & $0.05(-0.11,0.20)$ & $0.02(-0.03,0.06)$ & $0.05(-0.04,0.14$ \\
\hline SPARCC-SIJ (0-72) § & $-0.02(-0.13,0.09)$ & $0.01(-0.08,0.10)$ & $0.05(-0.01,0.11)$ & $0.01(-0.04,0.06)$ \\
\hline
\end{tabular}

१ Each joint graded 0-3

$\S$ Coefficients were estimated in the subgroup 
spondyloarthritis (axSpA) spectrum of patients i.e. including not only patients with AS but also those with non-radiographic axSpA.

Objectives: To estimate a robust mapping between ASDAS and EQ5D (3 level version) and to test its performance out of sample (external validation) in patients with axSpA.

Methods: Data from an electronic, prospective, nationwide Rheumatic Disease Portuguese Register (Reuma.pt) provided data pertaining to 1140 patients (5483 observations) with a confirmed diagnosis of axSpA was used to develop a model to predict EQ5D from the ASDAS score. We compared a range of different statistical models developed to deal with the complex distributional features of health utility data. A range of criteria examining model fit across the spectrum of disease severity were used to select preferred models. A smaller dataset for out of sample validation from the SPondyloArthritis Caught Early (SPACE) cohort was used, providing data from 317 patients (1225 observations) at five European centres.

Results: Characteristics of patients from the Reuma.pt and SPACE are presented in the table. There is a non-linear relationship between ASDAS and EQ5D. We found that a four component mixture model based on a bespoke distribution, with one component constrained to reflect the mass of observations at full health, was the best fitting of the ASDAS models estimated (figure). ASDAS squared and age squared featured as within component variables. The model demonstrated close fit to the observed data where ASDAS was less than 4 but diverged from the mean of the data where ASDAS was higher. There is a very limited data at this more severe level of disease activity. In the out of sample testing, the model continued to perform well overall and exhibited the same divergence from the observed data only where data was sparse.

Conclusion: There is a clear relationship between ASDAS and EQ5D that we were able to model reliably using bespoke mixture model based methods. There is more uncertainty regarding model fit at very high levels of disease activity owing to the relative paucity of data from patients in such disease activity state. Future analyses may wish to focus on these severely affected patients in order to improve the robustness of model estimates.

Table. Characteristics of patients from the Reuma.pt and SPACE datasets

\begin{tabular}{|c|c|c|c|c|c|c|c|c|c|c|}
\hline & \multicolumn{5}{|c|}{ REUMA $(n=1140)$} & \multicolumn{5}{|c|}{ SPACE $(n=317)$} \\
\hline & $\mathrm{N}$ & Mean & sd & $\min$ & $\max$ & $\mathrm{N}$ & mean & sd & $\min$ & $\max$ \\
\hline Age at visit (yrs) & 5483 & 46.58 & 11.99 & 17.70 & 82.70 & 1225 & 31.44 & 7.78 & 16.14 & 50.46 \\
\hline Number of visits & 5483 & 4.81 & 5.26 & 1.00 & 39.00 & 1225 & 4.05 & 1.60 & 1.00 & 8.00 \\
\hline ASDAS total score & 4886 & 2.02 & 0.97 & 0.60 & 6.30 & 1181 & 2.10 & 0.96 & 0.64 & 5.44 \\
\hline BASDAl total score & 5383 & 2.97 & 2.26 & 0.00 & 10.00 & 1211 & 3.27 & 2.20 & 0.00 & 9.80 \\
\hline BASFI total score & 5258 & 2.84 & 2.41 & 0.00 & 9.88 & 1205 & 1.92 & 2.09 & 0.00 & 9.30 \\
\hline EQ-5D-3L & 5483 & 0.70 & 0.26 & -0.59 & 1.00 & 1225 & 0.69 & 0.25 & -0.59 & 1.00 \\
\hline Proportion Male & 5483 & 0.56 & & & & 1225 & 0.50 & & & \\
\hline
\end{tabular}

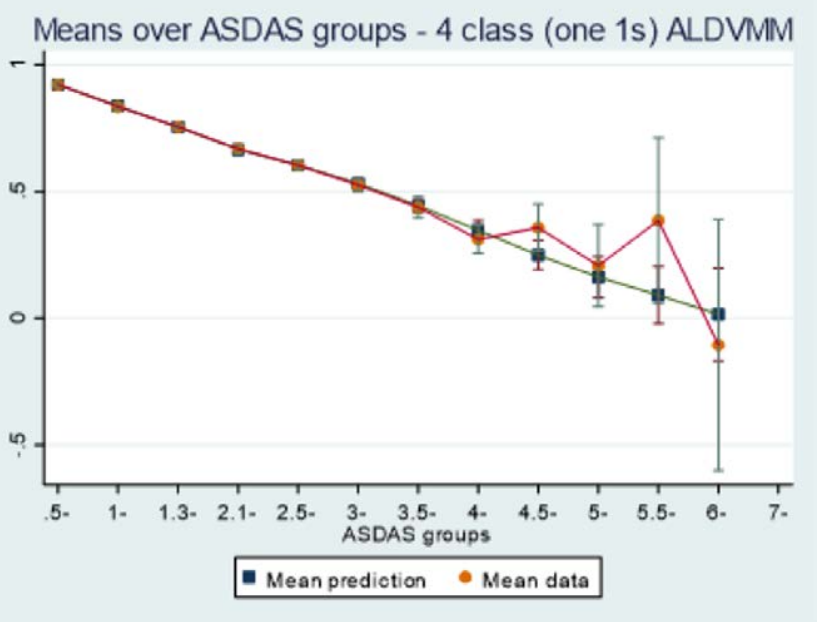

Figure. Mean observed versus fitted values for the preferred model mapping EQ5D-3L from ASDAS (Reuma.Pt dataset)

Acknowledgments: We would like to that all the contributors to the Reuma.Pt and SPACE datasets.

Disclosure of Interests: Monica Hernandez: None declared, Allan Wailoo: None declared, Georgios Chrysanthou: None declared, Pedro Carvalho: None declared, Désirée van der Heijde Consultant of: AbbVie, Amgen, Astellas, AstraZeneca, BMS, Boehringer Ingelheim, Celgene, Cyxone, Daiichi, Eisai, Eli-Lilly,
Galapagos, Gilead Sciences, Inc., Glaxo-Smith-Kline, Janssen, Merck, Novartis, Pfizer, Regeneron, Roche, Sanofi, Takeda, UCB Pharma; Director of Imaging Rheumatology BV, Maria Jose Santos Speakers bureau: Novartis and Pfizer Pedro M Machado Consultant of: PMM: Abbvie, Celgene, Janssen, Lilly, MSD, Novartis, Pfizer, Roche and UCB, Speakers bureau: PMM: Abbvie, BMS, Lilly, MSD, Novartis, Pfizer, Roche and UCB

DOI: 10.1136/annrheumdis-2020-eular.6196

\section{OP0079 \\ PRELIMINARY DEFINITION OF A POSITIVE MRI FOR STRUCTURAL LESIONS IN THE SACROILIAC JOINTS IN AXIAL SPONDYLOARTHRITIS}

W. P. Maksymowych ${ }^{1,2}$, X. Baraliakos ${ }^{3}$, U. Weber ${ }^{4}$, P. M. Machado ${ }^{5}$, S. Juhl Pedersen $^{6}$, J. Sieper ${ }^{7}$, S. Wichuk ${ }^{1}$, D. Poddubnyy ${ }^{7}$, M. Rudwaleit ${ }^{8}$, D. Van der Heijde $^{9}$, R. B. M. Landewé ${ }^{10}$, J. Paschke ${ }^{2}$, R. G. Lambert ${ }^{1}$, M. Ǿstergaard ${ }^{6}$. ${ }^{1}$ University of Alberta, Edmonton, Canada; ${ }^{2}$ CARE Arthritis, Edmonton, Canada; ${ }^{3}$ Rheumazentrum Ruhrgebiet, Herne, Germany; ${ }^{4}$ University of Southern Denmark, Sønderborg, Denmark; ${ }^{5}$ University College London, London, United Kingdom; ${ }^{6}$ Copenhagen University, København, Denmark; ${ }^{7}$ Charité - Universitätsmedizin Berlin, Berlin, Germany; ${ }^{8}$ Klinikum Bielefeld, Bielefeld Germany; ${ }^{9}$ Leiden University Medical Center (LUMC), Leiden, Netherlands; ${ }^{10}$ University of Amsterdam, Amsterdam, Netherlands

Background: There is lack of international consensus as to what defines a structural lesion on MRI of the sacroiliac joints (SIJ) typical of axial spondyloarthritis (axSpA). The ASAS MRI group has generated updated consensus lesion definitions that describe each of the MRI lesions in the SIJ ${ }^{1}$. These definitions have been evaluated by 7 readers from the ASAS-MRI group on MRI images from the ASAS Classification Cohort.

Objectives: We aimed to identify quantitative cut-offs based on numbers of slices and SIJ quadrants that define a positive MRI for structural lesions typical of $\operatorname{axSpA}$, the gold standard being majority central reader decision as to the presence of a structural lesion typical of axSpA with high confidence.

Methods: MRI structural lesions meeting ASAS definitions were recorded in an eCRF that comprises global assessment (structural lesion typical of axSpA present/absent and degree of confidence ( -4 (absent) to +4 (present)), and detailed scoring of lesions per SIJ quadrant. Detailed scoring was based only on assessment of DICOM images ( $n=148)$. We calculated sensitivity and specificity for numbers of SIJ quadrants and consecutive slices with erosion, sclerosis, and fat lesions where a majority of readers $(\geq 4 / 7)$ agreed as to the presence of a structural lesion typical of axSpA with high confidence $(\geq+3)$. We tested candidate lesion definitions for predictive diagnostic utility in cases assessed after 4.4 years of follow up by the local rheumatologist.

Results: Structural lesions typical of axSpA were observed by majority read in $33(32.4 \%)$ of 102 cases diagnosed with axSpA, and $3(6.8 \%)$ of 44 cases without axSpA and 29 cases were assigned a high degree of confidence ( $\geq$ +3 ) by a majority of readers. Cut-offs achieving specificity of $95 \%$ were erosion in $\geq 2$ consecutive slices (sensitivity $83 \%$ ), erosion $\geq 3$ SIJ quadrants (sensitivity $90 \%$ ), and fat lesion ( $\geq 1 \mathrm{~cm}$ horizontal depth) in $\geq 1$ SIJ quadrant (sensitivity $59 \%$ ) (Table). These had very high positive predictive values (>95\%) for diagnosis of axSpA in cases diagnosed by the rheumatologist after 4.4 years follow up.

Conclusion: ASAS-defined erosion in $\geq 2$ consecutive slices or in $\geq 3$ SIJ quadrants and ASAS-defined fat lesion with depth $>1 \mathrm{~cm}$ in $\geq 1$ SIJ quadrant are high priority candidates for defining an MRI structural lesion typical of axSpA. This will require similar assessment in additional axSpA cohorts.

References:

[1] Maksymowych et al. Ann Rheum Dis 2019; 78:1550-8.

Table 1. Majority readers agree structural lesion indicative of axSpA is present with confidence $\geq 3 / 4$ is the gold-standard external reference

\begin{tabular}{lcc}
\hline & Sensitivity & Specificity \\
\hline Erosion Score $\geq 1$ SIJ qdr & $93.1(77.2-99.2)$ & $80.6(72.4-87.3)$ \\
Erosion Score $\geq 2$ SIJ qdr & $93.1(77.2-99.2)$ & $90.8(84.1-95.3)$ \\
Erosion Score $\geq 3$ SIJ qdr & $89.7(72.6-97.8)$ & $95.8(90.5-98.6)$ \\
Erosion in 2 consecutive slices & $82.8(64.2-94.2)$ & $95.0(89.3-98.1)$ \\
Fat lesion $\geq 1$ SIJ qdr & $82.8(64.2-94.2)$ & $81.5(73.4-88.0)$ \\
Fat lesion $\geq 2$ SIJ qdr & $69.0(49.2-84.7)$ & $86.6(79.1-92.1)$ \\
Fat lesion $\geq 3$ SIJ qdr & $62.1(42.3-79.3)$ & $91.6(85.1-95.9)$ \\
Fat lesion in 2 consecutive slices & $55.2(35.7-73.6)$ & $93.3(87.2-97.1)$ \\
Fat lesion $(>1 \mathrm{~cm}$ depth) $\geq 1$ & $58.6(38.9-76.5)$ & $95.0(89.3-98.1)$ \\
Fat lesion $(>1 \mathrm{~cm}$ depth) $\geq 2$ & $55.2(35.7-73.6)$ & $95.8(90.5-98.6)$ \\
Fat lesion $(>1 \mathrm{~cm}$ depth) $\geq 3$ & $51.7(32.5-70.6)$ & $97.5(92.8-99.5)$ \\
Fat lesion $(>1 \mathrm{~cm}$ depth) in 2 consecutive slices & $48.3(29.4-67.5)$ & $97.5(92.8-99.5)$
\end{tabular}

Table. SIJ qdr: sacroiliac joint quadrant 